2016 Global Marketing Conference at Hong Kong Proceedings: 413 (July 2016) http://dx.doi.org/10.15444/GMC2016.04.05.02

\title{
AWAY FROM HOME: HOW LITTLE EMPERORS TRAVEL WITH GLOBAL BRANDS? CORE AND CONTEXTUAL MEANINGS OF GLOBAL BRANDS
}

\author{
Benedetta Cappellini, Royal Holloway University of London, UK ${ }^{1)}$ \\ Sameer Hosany, Royal Holloway University of London, UK \\ Dorothy Yen, Brunel University, UK \\ Qionglei Yu, Canterbury Christ Church University, UK
}

\begin{abstract}
This interpretive and longitudinal study investigates how a group of Chinese students consume global brands of American origins, in China and in the UK. More specifically, this research examines how meanings attached to global food brands travel abroad with consumers and investigates the relationship between brand consistency and brand meanings across national boundaries. Findings from a thematic analysis of longitudinal data collected through focus group interviews over a nine-month period, reveal that some brand meanings are context and culture specific (contextual meanings) while others meanings travel with consumers across borders (core meanings). Theoretically, this study shows how global brands provide a platform of structural meanings, ideas and practices that are global and globalising in themselves, allowing a degree of fluidity and adaptation in relation to the local context of consumption.
\end{abstract}

Keywords: travelling consumers, global brands, brand meanings, brand consistency, Little Emperors

\footnotetext{
${ }^{1)}$ Benedetta.Cappellini@rhul.ac.uk
} 